\title{
Filogenia molecular de las especies del subgénero Fissurella (Mollusca: Vetigastropoda) de la costa chilena
}

Molecular phylogeny of the species from the subgenus Fissurella (Mollusca: Vetigastropoda) found on the Chilean coast

\begin{abstract}
Alberto Olivares-Paz ${ }^{1,2}$, Javier Quinteiro² y Manuel Rey-Méndez²
${ }^{1}$ Departamento de Acuicultura, Facultad de Recursos del Mar, Universidad de Antofagasta, Casilla 170, Antofagasta, Chile. aolivares@uantof.cl

${ }^{2}$ Departamento de Bioquímica y Biología Molecular, CIBUS, Campus Vida, Universidad de Santiago de Compostela, 15782 Santiago de Compostela, España.javier.quinteiro@usc.es; manuel.rey.mendez@usc.es

Abstract.-Several species of the genus Fissurella coexist on the rocky intertidal substrate in the southeastern coast of the Pacific Ocean. Thirteen species are considered as valid, considering some variable and morphologically unstable species, which have historically allowed registering 58 specific names. This report describes the congruence degree existing between the current typological classification and molecular data obtained from nuclear and mitochondrial genes. Data includes sequences of the spacers ITS1 and ITS2 in the nuclear ribosomal operon and partial sequences of the mitochondrial gene ND1. Reconstruction of phylogenetic relations shows congruence between mitochondrial and nuclear data and allows us to clearly establish two groups of species, including polyphyletic species. The first group contains the 'latimarginata complex', which includes morphotypes of $F$. latimarginata, F. cumingi, F. bridgesii and F. oriens. In addition, the monophyletic species F. radiosa, F. pulchra and F. peruviana are included in this group. The second group corresponds to the complex 'costata-picta' that includes $F$. costata and $F$. picta. Other monophyletic species in this group were $F$. maxima in an intermediate position, $F$. limbata and $F$. nigra in a basal position. According to our results, $F$. crassa was situated in a basal position, i.e., close to root, within the phylogenetic tree. This data indicates the necessity of a taxonomic revision of this genus.
\end{abstract}

Key words: Taxonomy, Fissurellidae, sympatric species, genes

Resumen.- Varias especies del género Fissurella coexisten en simpatría en el sustrato rocoso de la región suroriental del Océano Pacífico. La taxonomía actual basada en caracteres morfológicos variables e inestables, considera 13 especies válidas para este género, los cuales históricamente han permitido registrar 58 nombres específicos. Este trabajo evalúa el grado de congruencia existente entre la actual clasificación tipológica y los datos moleculares obtenidos a partir de genes mitocondriales y nucleares. Estos datos incluyen la secuencia parcial del gen mitocondrial ND1 y la de los espaciadores ITS1 e ITS2 del operón ribosomal nuclear. La reconstrucción de las relaciones filogenéticas muestra una congruencia entre datos mitocondriales y nucleares y permite establecer claramente dos grupos de especies, que incluyen especies polifiléticas. En el primero se localiza el 'complejo latimarginata', que incluye indistintamente morfotipos de $F$. latimarginata, $F$. cumingi, $F$. bridgesii y $F$. oriens. Junto a esas especies polifiléticas se sitúan las monofiléticas $F$. radiosa, $F$. pulchra y $F$. peruviana. En el segundo grupo se sitúa el complejo 'costata-picta' que incluye a $F$. costata y $F$. picta. Las otras especies monofiléticas de este grupo son $F$. maxima, en posición intermedia $F$. limbata y $F$. nigra en posición basal. La especie $F$. crassa se sitúa en posición basal, i.e., próximo a la raíz del árbol filogenético. Estos datos indican la necesidad de una revisión taxonómica de este género.

Palabras clave: Taxonomía, Fissurellidae, especies simpátricas, genes 


\section{INTRODUCCIÓN}

La región de aguas templadas del Océano Pacífico suroriental incluye las provincias faunísticas Peruviana y Magallánica, con una zona templada transicional entre ambas (Balech 1954, Castilla 1979, Lancellotti \& Vásquez 1999). La corriente de Humboldt confiere a esta región una alta productividad y biodiversidad. Cada provincia faunística presenta endemismos con superposición en la distribución de las especies en la zona de transición (Lancellotti \& Vásquez 1999). La riqueza de esta región ha sido explotada por el hombre desde la colonización del área costera en el Eoceno (Vilaxa \& Corrales 1993), siendo las especies de moluscos del género Fissurella un habitual recurso alimentario al poseer un pie muscular muy desarrollado. En los últimos 5 años, el sector pesquero artesanal ha explotado un promedio anual de 1.900 ton, que aparece registrada mayoritariamente con el nombre genérico de Fissurella spp. (SERNAPESCA 2009) denominación que no diferencia los volúmenes de extracción de cada especie, en concordancia con las dificultades inherentes para la identificación de éstas mediante claves tipológicas (Vegas-Velez 1968).

Las especies del género Fissurella, popularmente llamadas 'lapas', coexisten en simpatría habitando el sustrato rocoso de la zona intermareal media a la submareal, son consumidores primarios y se alimentan de macroalgas (Bretos 1978, Osorio et al. 1988). Desde 1984 se reconocen y aceptan como válidas 13 especies: $F$. peruviana Lamarck, 1822; F. maxima Sowerby, 1835; F. limbata Sowerby, 1835; F. pulchra Sowerby, 1835; F. bridgesii Reeve, 1849; F. cumingi Reeve, 1849; F. latimarginata Sowerby, 1835; F. costata Lesson, 1831; F. crassa Lamarck, 1822; F. nigra Lesson, 1831; F. oriens Sowerby, 1835, F. picta (Gmelin, 1791); y F. radiosa Lesson, 1831 , organizadas en 3 grupos denominados $F$. peruviana, $F$. maxima y $F$. limbata pertenecientes al subgénero Fissurella 'sensu stricto' (McLean 1984). La taxonomía vigente se fundamenta en los caracteres de la concha tales como morfología, coloración, diseño y el tamaño y color del pie. Sin embargo, históricamente, la taxonomía de estas especies bajo la perspectiva de distintos autores ha llegado a originar un registro de 58 nombres específicos (McLean 1984). Los caracteres tipológicos son ampliamente variables y con frecuencia se superponen a nivel interespecífico. Así varían con la edad (tamaño) y presentan escasas diferencias entre los juveniles de distintas especies, lo cual limita la utilidad de las claves de identificación a los animales adultos (Vegas-Velez 1968). Además, la concha tiene una estructura que constituye una superficie muy favorable para la fijación de organismos epibiontes, los cuales encubren y deterioran los caracteres tipológicos (Bretos 1979, McLean 1984, Bretos et al. 1988, Bretos \& Chihuailaf 1990, Olivares et al. 1998).

En consecuencia, la taxonomía del subgénero Fissurella, sustentada en caracteres corporales, morfológicos, estructurales y de diseño de la concha, considerados variables e inconsistentes, generan controversias, y las especies actualmente reconocidas no están al margen de discrepancias. Recientemente, estudios de microscopía electrónica ponen en evidencia diferencias existentes en la ultraestructura del núcleo del espermatozoide entre las especies $F$. crassa, $F$. latimarginata y F. cumingi (Collado \& Brown 2003, 2005), las cuales podrían ser de valor taxonómico y permitirían validar el estatus de esas especies. Con el objetivo de llevar a cabo una autentificación genética de las diversas especies de lapas, destinadas a uso alimentario, el análisis de PCR-RFLP de secuencias del gen citocromo b mitocondrial mostró una incongruencia entre la taxonomía establecida y los datos patrones de RFLP observados. Así, especies taxonómicamente diferenciadas presentaron patrones de RFLP idénticos (Olivares-Paz et al. 2006)

La descripción formal de muchas especies no ha contado con el aporte de datos genético-moleculares debido a que han sido aplicados en las últimas dos décadas. Los estudios genéticos moleculares proveen mayor precisión en la determinación taxonómica y en la asignación de individuos a taxones concretos (Hillis 1987), siendo ambas técnicas complementarias y necesarias para la descripción de especies. Se plantea la hipótesis de que la incorporación de datos moleculares para la inferencia de las relaciones filogenéticas dentro del género Fissurella permitirán obtener una visión alternativa, pero incongruente con su actual sistemática. Así, frente a la discutible taxonomía del género Fissurella, el presente estudio evalúa el grado de congruencia entre la clasificación establecida en base a caracteres morfológicos (McLean 1984, Oliva \& Castilla 1992) y las relaciones filogenéticas obtenidas a partir de datos moleculares mitocondriales y nucleares.

${ }^{1}$ Anuarios Estadísticos de Pesca. Servicio Nacional de Pesca, Valparaíso. 2009,<http://www.sernapesca.cl> 


\section{Materiales y MÉTOdOS}

Los ejemplares de cada una de las 13 especies actualmente clasificadas dentro del subgénero Fissurella fueron recolectados entre la zona intermareal media y submareal, a una profundidad máxima de $20 \mathrm{~m}$, en las localidades indicadas en la Tabla 1. La identificación y asignación específica de ejemplares con fenotipos característicos, se realizó en base a los caracteres morfológicos de valor taxonómico (McLean 1984) y claves de identificación
(Oliva \& Castilla 1992). Los ejemplares fueron preservados en $70 \%$ etanol a temperatura ambiente y en refrigeración hasta su análisis. Se usaron como grupos externos ejemplares de las especies atlánticas Fissurella nimbosa Linnaeus, 1758 (Atlántico oeste), Fissurella schrammii Fischer, 1857 (Atlántico este) y Diodora graeca Linnaeus, 1758 (Atlántico nordeste) de la familia Fissurellidae (Tabla 1).
Tabla 1. Localización de las áreas de muestreo de los ejemplares analizados de las diferentes especies del género Fissurella. Se indica el tamaño muestral (N), sus coordenadas geográficas y el código de identificación / The location of sample areas for analyzed specimens of the subgenus Fissurella. Sample size (N), geographical coordinates and identification codes are shown

\begin{tabular}{|c|c|c|c|c|c|}
\hline Especie & $\mathrm{N}$ & Localidad & Latitud & Longitud & Código \\
\hline F. bridgesii Reeve, 1849 & $\begin{array}{l}2 \\
4\end{array}$ & $\begin{array}{l}\text { Caleta Camarones } \\
\text { LosVerdes (Iquique) }\end{array}$ & $\begin{array}{l}19^{\circ} 12^{\prime} \mathrm{S} \\
20^{\circ} 27^{\prime} \mathrm{S}\end{array}$ & $\begin{array}{l}70^{\circ} 17^{\prime} \mathrm{W} \\
70^{\circ} 12^{\prime} \mathrm{W}\end{array}$ & $\begin{array}{l}\text { FBRInCA } \\
\text { FBRIn }\end{array}$ \\
\hline F. costata Lesson, 1831 & $\begin{array}{l}2 \\
4 \\
2\end{array}$ & $\begin{array}{l}\text { Tilgo } \\
\text { La Isla de Algarrobo } \\
\text { Arco Cocholgue }\end{array}$ & $\begin{array}{l}29^{\circ} 31^{\prime} \mathrm{S} \\
33^{\circ} 21^{\prime} \mathrm{S} \\
36^{\circ} 35^{\prime} \mathrm{S}\end{array}$ & $\begin{array}{l}71^{\circ} 19^{\prime} \mathrm{W} \\
71^{\circ} 41^{\prime} \mathrm{W} \\
72^{\circ} 58^{\prime} \mathrm{W}\end{array}$ & $\begin{array}{l}\text { FCOSnTI } \\
\text { FCOSnAI } \\
\text { FCOSnTC }\end{array}$ \\
\hline F. crassa Lamarck, 1822 & $\begin{array}{l}2 \\
2 \\
2\end{array}$ & $\begin{array}{l}\text { LosVerdes (Iquique) } \\
\text { Coloso (Antofagasta) } \\
\text { Tilgo }\end{array}$ & $\begin{array}{l}20^{\circ} 27^{\prime} \mathrm{S} \\
23^{\circ} 44^{\prime} \mathrm{S} \\
29^{\circ} 31^{\prime} \mathrm{S}\end{array}$ & $\begin{array}{l}70^{\circ} 12^{\prime} \mathrm{W} \\
70^{\circ} 28^{\prime} \mathrm{W} \\
71^{\circ} 19^{\prime} \mathrm{W}\end{array}$ & $\begin{array}{l}\text { FCRAnI } \\
\text { FCRAnA } \\
\text { FCRAnTI }\end{array}$ \\
\hline F. cumingi Reeve, 1849 & $\begin{array}{l}3 \\
2 \\
2 \\
2 \\
2 \\
3 \\
4\end{array}$ & $\begin{array}{l}\text { Los Verdes (Iquique) } \\
\text { Punta Arenas } \\
\text { (Tocopilla) } \\
\text { Isla Pan de Azúcar } \\
\text { Tilgo } \\
\text { La Isla de Algarrobo } \\
\text { Isla Cochino. Polocue }\end{array}$ & $\begin{array}{l}20^{\circ} 27^{\prime} \mathrm{S} \\
21^{\circ} 38^{\prime} \mathrm{S} \\
26^{\circ} 10^{\prime} \mathrm{S} \\
29^{\circ} 31^{\prime} \mathrm{S} \\
33^{\circ} 21^{\prime} \mathrm{S} \\
41^{\circ} 50^{\prime} \mathrm{S} \\
41^{\circ} 53^{\prime} \mathrm{S}\end{array}$ & $\begin{array}{l}70^{\circ} 12^{\prime} \mathrm{W} \\
70^{\circ} 09^{\prime} \mathrm{W} \\
70^{\circ} 40^{\prime} \mathrm{W} \\
71^{\circ} 19^{\prime} \mathrm{W} \\
71^{\circ} 41^{\prime} \mathrm{W} \\
73^{\circ} 49^{\prime} \mathrm{W} \\
74^{\circ} 02^{\prime} \mathrm{W}\end{array}$ & $\begin{array}{l}\text { FCUMnI } \\
\text { FCUMnT } \\
\text { FCUMnPA } \\
\text { FCUMnTI } \\
\text { FCUMnAI } \\
\text { FCUMnIC } \\
\text { FCUMnPC }\end{array}$ \\
\hline F. latimarginata Sowerby, 1835 & $\begin{array}{l}2 \\
2 \\
3 \\
2 \\
2 \\
2 \\
2\end{array}$ & $\begin{array}{l}\text { Los Verdes (Iquique) } \\
\text { Punta Arenas } \\
\text { (Tocopilla) } \\
\text { Coloso (Antofagasta) } \\
\text { Isla Pan de Azúcar } \\
\text { Tilgo } \\
\text { La Isla de Algarrobo } \\
\text { Arco Cocholgue }\end{array}$ & $\begin{array}{l}20^{\circ} 27^{\prime} \mathrm{S} \\
21^{\circ} 38^{\prime} \mathrm{S} \\
23^{\circ} 44^{\prime} \mathrm{S} \\
26^{\circ} 10^{\prime} \mathrm{S} \\
29^{\circ} 31^{\prime} \mathrm{S} \\
33^{\circ} 21^{\prime} \mathrm{S} \\
36^{\circ} 35^{\prime} \mathrm{S}\end{array}$ & $\begin{array}{l}70^{\circ} 12^{\prime} \mathrm{W} \\
70^{\circ} 09^{\prime}, \mathrm{W} \\
70^{\circ} 28^{\prime} \mathrm{W} \\
70^{\circ} 40^{\prime} \mathrm{W} \\
71^{\circ} 19^{\prime} \mathrm{W} \\
71^{\circ} 41^{\prime} \mathrm{W} \\
72^{\circ} 58^{\prime} \mathrm{W}\end{array}$ & $\begin{array}{l}\text { FLATnI } \\
\text { FLATnT } \\
\text { FLATnC } \\
\text { FLATnPA } \\
\text { FLATnTI } \\
\text { FLATnAI } \\
\text { FLATnTC }\end{array}$ \\
\hline F. limbata Sowerby, 1835 & $\begin{array}{l}2 \\
2 \\
2 \\
1\end{array}$ & $\begin{array}{l}\text { Los Verdes (Iquique) } \\
\text { Coloso (Antofagasta) } \\
\text { Tilgo } \\
\text { La Isla de Algarrobo }\end{array}$ & $\begin{array}{l}20^{\circ} 27^{\prime} \mathrm{S} \\
23^{\circ} 44^{\prime} \mathrm{S} \\
29^{\circ} 31^{\prime} \mathrm{S} \\
33^{\circ} 21^{\prime} \mathrm{S}\end{array}$ & $\begin{array}{l}70^{\circ} 12^{\prime} \mathrm{W} \\
70^{\circ} 28^{\prime}, \mathrm{W} \\
71^{\circ} 19^{\prime} \mathrm{W} \\
71^{\circ} 41^{\prime} \mathrm{W}\end{array}$ & $\begin{array}{l}\text { FLIMnI } \\
\text { FLIMnC } \\
\text { FLIMnTI } \\
\text { FLIMC2AI }\end{array}$ \\
\hline F. maxima Sowerby, 1835 & $\begin{array}{l}2 \\
2 \\
2 \\
2\end{array}$ & $\begin{array}{l}\text { Coloso (Antofagasta) } \\
\text { Tilgo } \\
\text { La Isla de Algarrobo } \\
\text { Los Bajos }\end{array}$ & $\begin{array}{l}23^{\circ} 44^{\prime} \mathrm{S} \\
29^{\circ} 31^{\prime} \mathrm{S} \\
33^{\circ} 21^{\prime} \mathrm{S} \\
33^{\circ} 54^{\prime} \mathrm{S}\end{array}$ & $\begin{array}{l}70^{\circ} 28^{\prime}, \mathrm{W} \\
71^{\circ} 19^{\prime}, \mathrm{W} \\
71^{\circ} 41^{\prime} \mathrm{W} \\
71^{\circ} 50^{\prime} \mathrm{W}\end{array}$ & $\begin{array}{l}\text { FMAXnA } \\
\text { FMAXnTI } \\
\text { FMAXnAI } \\
\text { FMAXnPI }\end{array}$ \\
\hline F. nigra Lesson, 1831 & 2 & Isla Kalau & $49^{\circ} 26^{\prime} \mathrm{S}$ & $75^{\circ} 30^{\prime} \mathrm{W}$ & FNIGnIK \\
\hline F. oriens Sowerby, 1835 & $\begin{array}{l}2 \\
2\end{array}$ & $\begin{array}{l}\text { Calbuco } \\
\text { Pargua }\end{array}$ & $\begin{array}{l}41^{\circ} 46^{\prime} \mathrm{S} \\
41^{\circ} 48^{\prime} \mathrm{S}\end{array}$ & $\begin{array}{l}73^{\circ} 30^{\prime} \mathrm{W} \\
73^{\circ} 28^{\prime} \mathrm{W}\end{array}$ & $\begin{array}{l}\text { FORInCC } \\
\text { FORInP }\end{array}$ \\
\hline F. peruviana Lamarck, 1822 & 4 & La Rinconada & $23^{\circ} 28^{\prime} \mathrm{S}$ & $70^{\circ} 30^{\prime} \mathrm{W}$ & FPERn \\
\hline F. picta (Gmelin, 1791) & $\begin{array}{l}2 \\
2\end{array}$ & $\begin{array}{l}\text { Los Bajos } \\
\text { Punta Quillagua }\end{array}$ & $\begin{array}{l}33^{\circ} 54^{\prime} \mathrm{S} \\
41^{\circ} 35^{\prime} \mathrm{S}\end{array}$ & $\begin{array}{l}71^{\circ} 50^{\prime}, \mathrm{W} \\
73^{\circ} 48^{\prime} \mathrm{W}\end{array}$ & $\begin{array}{l}\text { FPICnPI } \\
\text { FPICnPQ }\end{array}$ \\
\hline F. pulchra Sowerby, 1835 & $\begin{array}{l}2 \\
2 \\
2\end{array}$ & $\begin{array}{l}\text { Caleta Camarones } \\
\text { Los Verdes (Iquique) } \\
\text { Tilgo }\end{array}$ & $\begin{array}{l}19^{\circ} 12^{\prime} \mathrm{S} \\
20^{\circ} 27^{\prime} \mathrm{S} \\
29^{\circ} 31^{\prime} \mathrm{S}\end{array}$ & $\begin{array}{l}70^{\circ} 17^{\prime} \mathrm{W} \\
70^{\circ} 12^{\prime} \mathrm{W} \\
71^{\circ} 19^{\prime} \mathrm{W}\end{array}$ & $\begin{array}{l}\text { FPULnCA } \\
\text { FPULnI } \\
\text { FPULnTI }\end{array}$ \\
\hline F. radiosa Lesson, 1831 & 2 & Isla Cochino & $41^{\circ} 50^{\prime} \mathrm{S}$ & $73^{\circ} 49^{\prime} \mathrm{W}$ & FRADnIC \\
\hline F. nimbosa Linnaeus, 1978 & 3 & Venezuela & $11^{\circ} 02^{\prime} \mathrm{N}$ & $63^{\circ} 53^{\prime} \mathrm{W}$ & FNIMn \\
\hline F. schrammii Fischer, 1857 & 6 & Cabo verde & $16^{\circ} 05^{\prime} \mathrm{N}$ & $22^{\circ} 50^{\prime} \mathrm{W}$ & FSCHn \\
\hline D. graeca Linnaeus, 1758 & 1 & Aguiño, España & $42^{\circ} 31^{\prime} \mathrm{N}$ & $9^{\circ} \mathrm{W}$ & DGRAn \\
\hline
\end{tabular}

Vol. 46, N³, 2011 
Un fragmento (30-40 mg) del pie de cada ejemplar fue utilizado para el aislamiento del ADN total siguiendo el protocolo descrito para el uso del DNeasy Tissue Kit (Qiagen). El tejido muscular fue digerido con proteinasa $\mathrm{K}\left(600 \mathrm{mAU} \mathrm{mL}^{-1}\right)($ Qiagen $)$ a $55^{\circ} \mathrm{C}$ durante $15 \mathrm{~h}$ y el ADN eluido se almacenó a $-20^{\circ} \mathrm{C}$, para ser usado en las distintas amplificaciones. La integridad del ADN aislado fue verificada por electroforesis en gel de agarosa al $1 \%$, teñido con bromuro de etidio y visualizándose bajo luz ultravioleta. La concentración y pureza del ADN se determinó a través de la absorbancia a $260 \mathrm{~nm}$ y la relación 260/280 nm, respectivamente, en un espectrofotómetro Smart SpecTM (Bio-Rad). Mediante PCR (Saiki et al. 1988) fueron amplificados un fragmento del gen mitocondrial de la subunidad 1 de la NADH deshidrogenasa (ND1), incluyendo parte del ARNt-Leu adyacente, y los espaciadores ITS1 e ITS2 del operon ribosomal nuclear. La amplificación en el gen ND1 fue llevada a cabo mediante los cebadores de diseño propio FISS1-ND1F (5'GGTGGCAGAATAAGTGCGTTAG-3') y FISS2-ND1R (5'TACAGCCCGAATTGCCCC-3'). La amplificación de ITS1 e ITS2 se ha obtenido mediante PCR anidada. En la primera PCR fueron usados los cebadores 18d-5' (Palumbi 1998) y BAB28S-2R (Quinteiro et al. 2005). En una segunda reacción fueron combinados los cebadores $18 \mathrm{~d}-5$ ' y BAB5.8S-1R (5'-GCCGCCATATGCGTTCA-3'), de diseño propio, junto con el juego BAB5.8S-1F (5'TGAACGCATATGGCGGC-3'), complementario del anterior, y BAB28S-2R, para la amplificación de ITS1 e ITS2, respectivamente.

Cada reacción de amplificación se hizo en un volumen total de 12,5 $\mu \mathrm{L}$ con tampón Promega 1x; 2,5 mM MgCl2; $200 \mu \mathrm{M}$ dNTPs; $0,2 \mu \mathrm{M}$ cebadores específicos de cada fragmento; 0,025 unidades de Taq DNA polimerasa (Promega); 40-50 ng de ADN total. El perfil de PCR fue: $94^{\circ} \mathrm{C}, 3 \mathrm{~min} ; 30$ ciclos de $94^{\circ} \mathrm{C}, 40 \mathrm{seg} ; 50^{\circ} \mathrm{C}, 40 \mathrm{seg} ; 72^{\circ} \mathrm{C}$, $100 \mathrm{seg} ; 72^{\circ} \mathrm{C}, 7 \mathrm{~min}$. En la amplificación de ITS la temperatura de fusión se incrementó hasta los $60^{\circ} \mathrm{C}$.

Los productos de secuenciación fueron enzimáticamente purificados con ExoSAP-IT (Amersham-Biosciences) y secuenciadas las dos hebras con BigDye Terminator v3.1 (Applied Biosystems). Los productos de extensión fluorescentes fueron separados mediante electroforesis y detectados empleando un secuenciador automático ABI PRISM 377 (Applied Biosystems).

Las secuencias fueron revisadas y alineadas usando el programa BioEdit 7.01 (Hall 1999). La estimación de la diversidad nucleotídica, diversidad haplotípica, sitios polimórficos y frecuencias nucleotídicas fue llevada a cabo utilizando el programa DnaSP v4.10 (Rozas et al. 2003). La reconstrucción de las relaciones filogenéticas entre secuencias se basó en el criterio de distancias. Se llevó a cabo la selección del modelo evolutivo adecuado para el análisis de los juegos de secuencias del gen mitocondrial ND1 mediante el programa ModelTest 3.6 (Posada \& Crandall 1998) y PAUP* $4.0 \mathrm{~b} 10$ (Swofford 2002). Se tuvieron en cuenta tanto los resultados obtenidos mediante la aplicación de criterio de Akaike como mediante el análisis jerarquizado de los diversos modelos, basado en el test de relación de verosimilitudes (hLRT) (Posada \& Crandall 1998). El modelo seleccionado se corresponde con el modelo GTR, con I = 0,293 y $\alpha=$ 0,534. A continuación se implementó el modelo evolutivo en PAUP* 4.0b10 (Swofford 2002) y se procedió a la obtención de la topología mediante NJ, obteniéndose el árbol consensuado 'majority-rule' de los análisis de 'bootstraping', manteniendo grupos con menores valores del $50 \%$ pero compatibles con el árbol. El número de replicaciones fue de 2000. En el caso de las secuencias nucleares correspondientes a los ITS1 e ITS2, se utilizaron las distancias obtenidas bajo un modelo de Tamura-Nei (Tamura \& Nei 1993).

\section{Resultados}

\section{Análisis de las Secuencias}

Se obtuvo un conjunto de 99 secuencias mitocondriales (gen ND1) para individuos de las 13 especies actualmente reconocidas del género Fissurella. El alineamiento para estas secuencias posee $423 \mathrm{pb}$, incluyendo parte del gen ARNt-Leu y ND1, (Números de acceso del Genbank: AY040977 - AY941071), carece de sitios vacíos e inserciones; los primeros $21 \mathrm{pb}$ corresponden a ARNtLeu y la traducción de los restantes corresponde a un fragmento polipeptídico de 134 aminoácidos, de los 315 mencionados para esta enzima en Haliotis rubra (AY 588938). Las secuencias tienen 211 (74\%) sitios invariables у 109 (26\%) sitios variables; de estos últimos 101 corresponden al tipo informativo para parsimonia y 8 al de singleton. En este juego total de datos mitocondriales se han detectado 49 haplotipos distintos, con homogeneidad en la frecuencia de las bases $\left(\chi^{2}=26,02\right.$; g.l. $=69 ; P=1,0)$.

El valor promedio de distancias genéticas entre las secuencias codificantes mitocondriales del gen ND1 es $0,106 \pm 0,008$. A nivel intraespecífico, las distancias estimadas en base a este gen, varían desde 0 a 0,015 . El mayor valor intraespecífico es obtenido en la especie $F$. 
nigra, mientras que los valores mínimos se obtienen entre las especies F. latimarginata y $F$. cumingi, e incluyendo a $F$. bridgesii y $F$. oriens. De forma similar, valores mínimos de distancias $(0,002)$ se obtienen entre $F$. picta y F. costata. La divergencia media dentro del grupo de especies con distribución en el Pacífico Sudoriental se sitúa en 8,5\%, con un valor máximo de 14,2\% (Tabla 2).

Las secuencias de un alelo detectado por cada especie, correspondiente a los interespaciadores ITS1 e ITS2, permitieron obtener un alineamiento de 323 y $293 \mathrm{pb}$, respectivamente. En ambas secuencias los polimorfismos de longitud aparecen en $F$. crassa, destacando una inserción común mayor de $10 \mathrm{pb}$ en el ITS1. Los valores medios de divergencia genética son idénticos para las dos secuencias (ITS1: 0,051 $\pm 0,006$; ITS2: 0,050 $\pm 0,006$ ).

\section{RECONSTRUCCIONES FILOGENÉTICAS}

Tras la reconstrucción filogenética, basada en las secuencias del gen ND1, se observan, entre las especies con distribución en el SE Pacífico, dos grupos de clados
(I y II), y un clado basal que comprende a la especie $F$. crassa. En el interior del grupo I se distingue el complejo de especies denominado 'complejo latimarginata', integrado por especies morfológicamente identificadas como F. latimarginata, F. cumingi, F. oriens y F. bridgesii, cuyos individuos se agrupan polifiléticamente sin agruparse en congruencia con los morfotipos correspondientes a cada especie. En contraste, los individuos incluidos en los taxones $F$. radiosa, F. pulchra y $F$. peruviana se agrupan en sus clados respectivos. El grupo II de especies contiene el 'complejo costata - picta', polifiléticamente formado por individuos morfológicamente asignados a $F$. costata y $F$. picta y cuya determinación taxonómica específica ha sido establecida en base a caracteres morfológicos. Se incluye además, como clado hermano a este complejo, F. maxima, en posición intermedia $F$. limbata y en $F$. nigra en posición basal. El clado de $F$. crassa, aparece independiente de los grupos I y II de especies con soportes de replicación del $100 \%$. En un clado divergente se sitúan las especies de distribución atlántica, F. nimbosa y F. schrammii (Fig. 1).

Tabla 2. Matriz de distancias $(p)$ netas interespecíficas obtenidas a partir de secuencias del ND1 para las especies analizadas del género Fissurella. Por encima de la diagonal se muestran los valores de EE. (Error Estándar), estimados mediante 500 replicaciones / Matrix for the net distances (p) observed from ND1 sequences in the analyzed species of the genus Fissurella. Standard Error (SE) values, estimated after 500 replications, are above the diagonal

\begin{tabular}{llcccccccccccccc}
\hline Especies & 1 & 2 & 3 & 4 & 5 & 6 & 7 & 8 & 9 & 10 & 11 & 12 & 13 & 14 & 15 \\
\hline 1 F. schrammii & & 0,021 & 0,020 & 0,021 & 0,020 & 0,020 & 0,022 & 0,021 & 0,020 & 0,021 & 0,020 & 0,020 & 0,020 & 0,020 & 0,020 \\
2 F. nimbosa & 0,233 & & 0,022 & 0,022 & 0,022 & 0,022 & 0,021 & 0,022 & 0,022 & 0,022 & 0,022 & 0,022 & 0,022 & 0,022 & 0,022 \\
3 F. limbata & 0,263 & 0,295 & & 0,011 & 0,015 & 0,010 & 0,013 & 0,008 & 0,014 & 0,014 & 0,014 & 0,014 & 0,014 & 0,014 & 0,014 \\
4 F. picta & 0,266 & 0,296 & 0,061 & & 0,017 & 0,000 & 0,013 & 0,010 & 0,015 & 0,015 & 0,015 & 0,015 & 0,015 & 0,015 & 0,015 \\
5 F. peruviana & 0,245 & 0,275 & 0,115 & 0,142 & & 0,017 & 0,015 & 0,016 & 0,015 & 0,012 & 0,012 & 0,012 & 0,012 & 0,012 & 0,012 \\
6 F. costata & 0,265 & 0,292 & 0,058 & 0,000 & 0,141 & & 0,013 & 0,010 & 0,015 & 0,015 & 0,015 & 0,015 & 0,015 & 0,015 & 0,015 \\
7 F. nigra & 0,260 & 0,258 & 0,082 & 0,081 & 0,115 & 0,080 & & 0,012 & 0,013 & 0,014 & 0,014 & 0,015 & 0,015 & 0,014 & 0,015 \\
8 F. maxima & 0,261 & 0,288 & 0,033 & 0,052 & 0,128 & 0,051 & 0,072 & & 0,014 & 0,015 & 0,015 & 0,014 & 0,014 & 0,014 & 0,014 \\
9 F. crassa & 0,232 & 0,259 & 0,109 & 0,117 & 0,103 & 0,116 & 0,092 & 0,103 & & 0,014 & 0,014 & 0,014 & 0,014 & 0,014 & 0,014 \\
10 F. radiosa & 0,232 & 0,269 & 0,103 & 0,111 & 0,074 & 0,110 & 0,093 & 0,116 & 0,097 & & 0,008 & 0,011 & 0,011 & 0,011 & 0,011 \\
11 F. pulchra & 0,237 & 0,276 & 0,103 & 0,114 & 0,074 & 0,112 & 0,104 & 0,111 & 0,102 & 0,027 & & 0,010 & 0,010 & 0,010 & 0,010 \\
12 F. oriens & 0,245 & 0,272 & 0,098 & 0,120 & 0,073 & 0,118 & 0,118 & 0,108 & 0,096 & 0,056 & 0,051 & & 0,003 & 0,002 & 0,002 \\
13 F. bridgesii & 0,249 & 0,274 & 0,103 & 0,125 & 0,070 & 0,123 & 0,117 & 0,107 & 0,093 & 0,057 & 0,053 & 0,004 & & 0,001 & 0,001 \\
14 F. cumingi & 0,246 & 0,271 & 0,098 & 0,121 & 0,069 & 0,119 & 0,115 & 0,103 & 0,092 & 0,055 & 0,050 & 0,002 & 0,001 & & 0,000 \\
15 F. latimarginata & 0,249 & 0,274 & 0,101 & 0,124 & 0,069 & 0,121 & 0,116 & 0,105 & 0,093 & 0,057 & 0,052 & 0,003 & 0,001 & 0,000 & \\
\hline
\end{tabular}




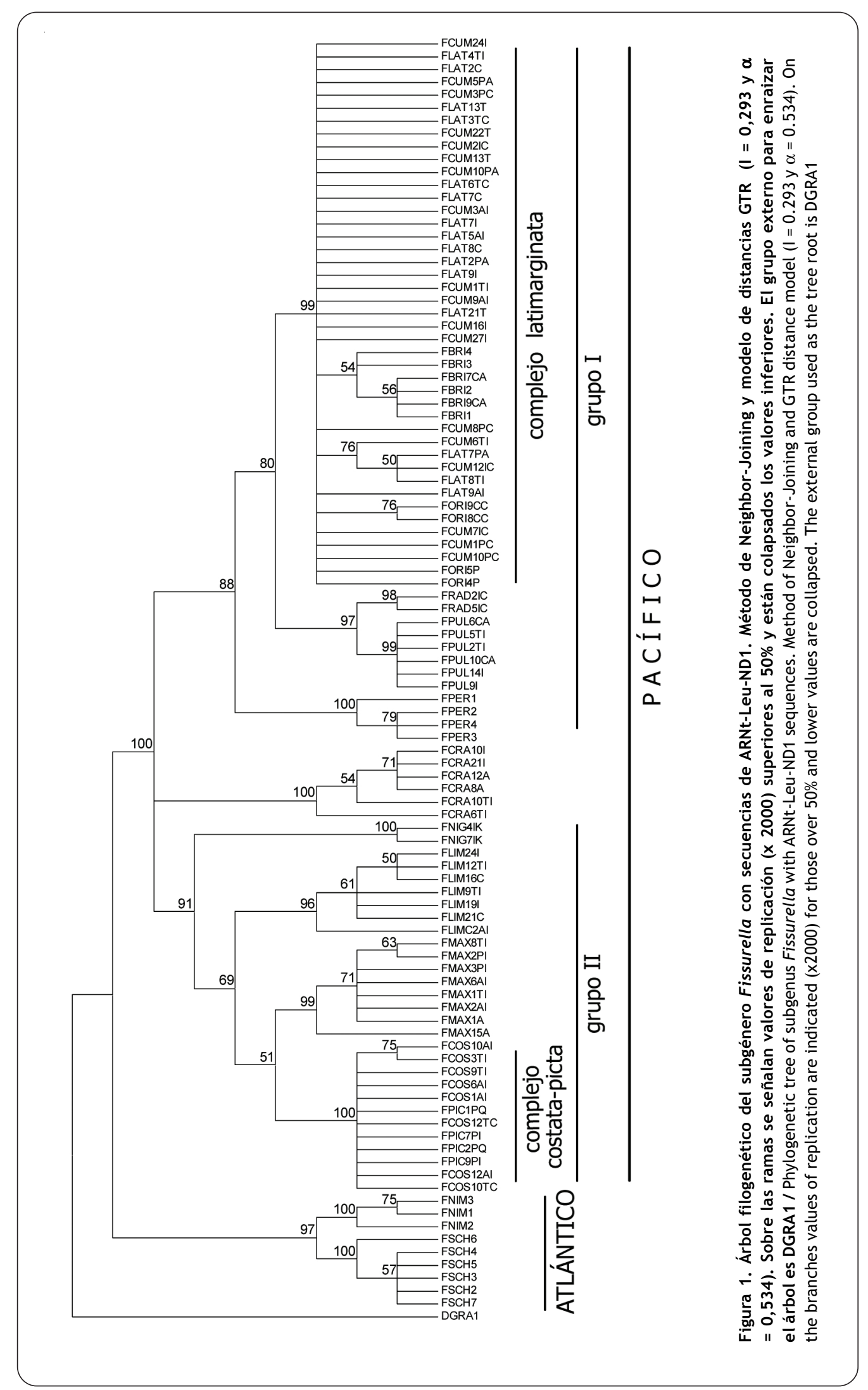


Las relaciones filogenéticas basadas en las secuencias de un alelo para cada especie de ITS 1 e ITS2 concatenados, permiten reconstruir un patrón filogenético similar al inferido a partir de las secuencias mitocondriales, siendo reconocibles los grupos I y II definidos para la topología mitocondrial. La mayoría de los nodos, son soportados por escasos valores de replicación y con escasa longitud en la mayoría de las ramas. Sin embargo, se reconoce la agrupación del 'complejo latimarginata' y la posición cercana a éste de las especies $F$. radiosa y $F$. pulchra. El otro grupo compacto obtenido es el clado que agrupa a $F$. costata y $F$. picta frente a $F$. limbata y $F$. maxima. Por otro lado, en posiciones basales y divergentes se sitúan $F$. peruviana, $F$. nigra y $F$. crassa (Fig. 2). La aplicación de metodologías alternativas de reconstrucción filogenética, tales como máxima parsimonia, máxima verosimilitud o inferencia bayesiana, conlleva la obtención de idénticos resultados (OlivaresPaz 2007).

\section{Discusión}

\section{GRUPOS DE ESPECIES}

Las 13 especies de Fissurella del Pacífico Sudoriental, se organizaron en torno a dos clados (grupos I y II), que no muestran congruencia con los grupos de especies $F$. peruviana, F. maxima y F. limbata definidos por McLean
(1984), en base al grosor relativo de las capas de aragonita y calcita y a la complejidad de la escultura radial y secundarias. Adicionalmente, el grupo I, comprende especies del grupo de $F$. maxima ( $F$. latimarginata, $F$. cumingi, $F$. oriens y $F$. radiosa) y del grupo $F$. limbata $(F$. pulchra y $F$. bridgesii). Del mismo modo, el grupo II, incluye especies del grupo $F$. maxima ( $F$. maxima, $F$. costata y $F$. picta) y del grupo $F$. limbata (F. limbata). Esta situación, resalta la inconsistencia en considerar la estructura de la concha para establecer relaciones y agrupaciones entre especies de Fissurella. Se evidencia así que las relaciones filogenéticas inferidas por metodologías moleculares no siempre son congruentes con las establecidas en base a caracteres morfológicos, como ha sido previamente constatado en otros estudios (Avise 1994, Schiaparelli et al. 2005).

Por otra parte, los dos grupos de especies no muestran concordancia con su distribución geográfica, descrita para las provincias faunísticas malacológicas de la región (McLean 1984) y, por el contrario, engloban especies de ambas provincias. Así, el grupo I incluye especies de la provincia Peruana: F. latimarginata, $F$. cumingi, $F$. bridgesii, $F$. pulchra y $F$. peruviana y de la provincia Magallánica: $F$. oriens y $F$. radiosa; mientras que en el grupo II, se encuentran especies de la provincia Peruana: $F$. maxima, F. limbata y $F$. costata, y de la Magallánica $F$. picta y F. nigra.

Figura 2. Árbol elaborado con secuencias de los interespaciadores ITS1 e ITS2, mostrando las relaciones entre especies de Fissurella del Pacífico Sudoriental usando como grupo externo a $F$. nimbosa del Atlántico. Método de Neighbor-Joining y modelo de distancia Tamura-NEi. Los valores de replicación (x 2000) se indican sobre las ramas / The tree was made with ITS1 and ITS2 interspacer sequences and shows the relationships between species of Fissurella from the south-eastern Pacific Ocean, using $F$. nimbosa from the Atlantic Ocean as an external group. Method of NeighborJoining and Tamura-Nei distance model. Replication values (x 2000) are shown on the branches

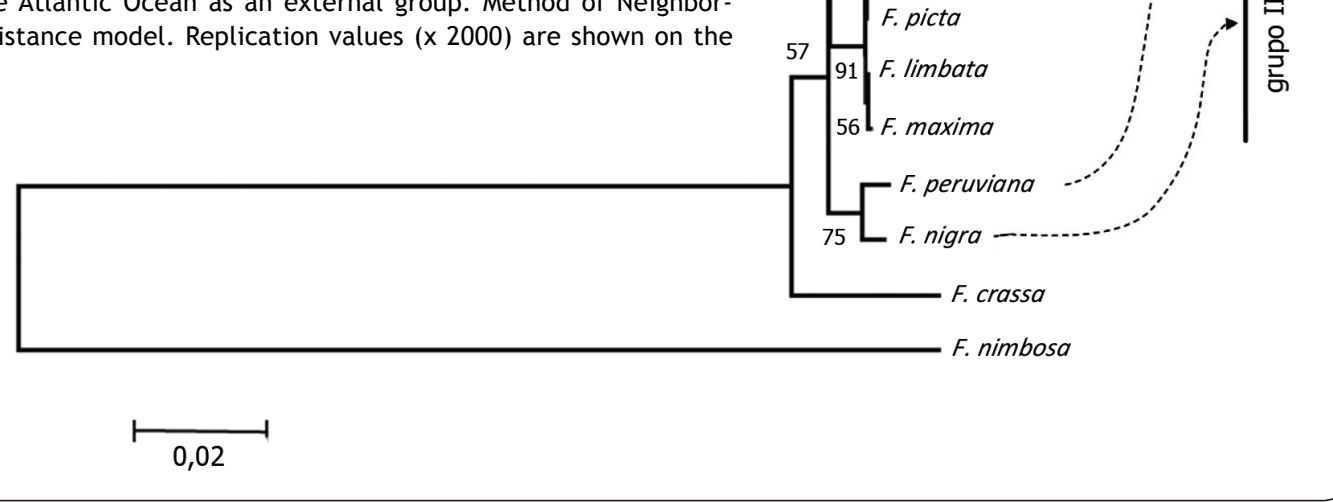


Del mismo modo, tampoco las especies muestran relaciones de asociación con la zonación vertical del área litoral en la que habitan (Bretos 1980, McLean 1984) encontrándose que las estrictamente intermareales $F$. crassa se localiza en el grupo I y es hermana del conjunto de especies de este grupo, mientras que $F$. limbata y $F$. picta en el grupo II. Las restantes 10 especies que comparten su ciclo vital entre el hábitat intermarealsubmareal, se distribuyen en asociaciones ya sea en el grupo I o II.

Estas evidencias indican que las asociaciones de las especies del subgénero Fissurella de Chile, realizadas en base a datos moleculares, no se relacionan con las características ambientales de las regiones faunísticas ni con los microambientes zonales verticales de la región costera del litoral Pacífico Sudoriental. La falta de concordancia entre los patrones taxonómicos planteados, en base a características de composición y estructura de la concha, y las relaciones filogenéticas estimadas a partir de los datos moleculares, se debe a dificultades inherentes a los caracteres morfológicos utilizados. Aunque McLean (1984) recurre al uso sistemático de ciertas características, tales como presencia relativa de las capas de calcita y aragonita, y caracteres asociados de la concha, también indica la dependencia de esos caracteres del medio ambiente, ya que la deposición relativa de calcita y aragonita en la concha, es un proceso dependiente de la temperatura, por ejemplo las especies tropicales, presentan una única capa de aragonita, mientras que las especies de la costa chilena presentan la capa externa calcítica y la interna aragonítica. Además, en especies de Mytilus y Littorina la deposición de calcita incrementa con la latitud (Lowenstam 1954) y específicamente dentro del género Fissurella, la especie F. picta del Estrecho de

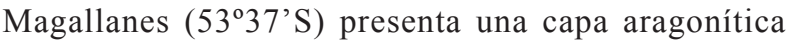
sensiblemente más fina que especímenes recolectados a $42^{\circ} 42^{\prime}$ 'S (McLean 1984). La variabilidad medioambiental de la relación calcita-aragonita, no sólo afecta a tal carácter, sino que probablemente afecta a caracteres relacionados y de uso en la sistemática tradicional de este género, tales como la estructura radial de las costillas, su complejidad y coloración.

\section{Congruencia entre especie morfológica y FILOGENÉTICA}

Los análisis de divergencia genética y la reconstrucción de las relaciones filogenéticas realizados con secuencias provenientes de las 13 especies, tipológicamente y taxonómicamente reconocidas, permitieron establecer 9 unidades filogenéticas para el subgénero Fissurella. De ellas, 7 muestran coincidencia de identidad entre las definiciones en base a caracteres morfológicos dados por McLean (1984) y las que cumplen con los atributos filogenéticos de especie (Cracraft 1983, Avise 1994). Estas especies son: F. crassa, F. nigra, F. maxima, F. limbata, $F$. peruviana, $F$. pulchra y $F$. radiosa. En contradicción, las otras seis especies muestran incongruencia entre la nomenclatura taxonómica y filogenética molecular, lo cual quedó reflejado en el establecimiento de dos grupos de especies filogenéticas: el complejo latimarginata formado por las especies morfológicas $F$. latimarginata, $F$. cumingi, F. bridgesii y $F$. oriens y el complejo $F$. costata - F. picta. Estas diferencias, tienen su origen en las variaciones morfológicas entre los individuos con la generación histórica de más de un nombre para la misma especie (Pérez-Farfante 1952, Marincovich 1973, RamírezBoehme 1974, McLean 1984). Aunque, McLean (1984), definió una serie de caracteres de valor taxonómico para las especies, con frecuencia ejemplares divergentes del holotipo descrito, de especies diferentes, comparten atributos morfológicos siendo difícil asignarlos a una determinada especie (Vegas-Velez 1968, Guzmán et al. 1998, Olivares-Paz et al. 2006). Previamente $F$. cumingi fue considerada una variedad de color de $F$. latimarginata y ambas especies comparten aspectos morfológicos de la concha y, en algunas variantes individuales, se encuentra algún patrón de la concha muy similar. Del mismo modo, el diseño de la concha puede ser confundido entre $F$. latimarginata y $F$. bridgesii, y el de esta especie con F. oriens.

De igual manera en el complejo de especies 'costata picta' los especímenes comparten una semejante morfología de concha y otros caracteres de la misma incluidos la coloración, aspecto de los rayos, grosor y amplitud de las costillas, los cuales a menudo muestran una amplia variabilidad entre animales, siendo difícil la asignación específica. Para $F$. picta se reconocen dos subespecies y los ejemplares considerados en este estudio corresponden a los del área de $F$. picta lata, desconociéndose si la subespecie $F$. picta picta, del área de Magallanes, podría ser parte de este complejo. Es posible que las diferencias morfológicas existentes en estas especies sean una consecuencia de las características específicas del medio en que viven, las cuales varían desde el intermareal rocoso rodeado de arena en que se encuentra $F$. bridgesii, al intermareal rocoso abierto y submareal de las otras especies. Las variaciones de las condiciones ambientales, han sido 
mencionadas como responsables de significativas diferenciaciones fenotípicas entre las poblaciones que viven en medios intermareales heterogéneos (Sokolova \& Boulding 2004) lo cual ha sido demostrado en el gasterópodo Scurria parasitica, un epibionte de Fissurella y de otros invertebrados marinos, que presenta morfología variable según el medio en que habita, pero todos los morfotipos distintos poseen el mismo haplotipo mitocondrial (Espoz et al. 2004). Un caso extremo de la plasticidad morfológica en gasterópodos lo evidencian Lymnaea peregra y L. ovata, las cuales viven en hábitats diferentes y difieren en características de la concha, pero en similares condiciones de laboratorio convergen en morfología de la concha al cabo de dos generaciones (Wullschleger \& Jokela 2001).

Los datos moleculares, mitocondriales y nucleares, indican la necesidad de revisar la taxonomía de este género, Fissurella, y revisar los caracteres diagnósticos que permitan el reconocimiento de especies a través de la morfología y morfometría, y reconsiderar el estatus taxonómico de las especies del 'complejo latimarginata' (F. latimarginata, F. cumingi, F. oriens y F. bridgesii) y del 'complejo costata-picta' (F. costata y F. picta).

\section{Agradecimientos}

Los autores quieren expresar su agradecimiento a todos los colegas que colaboraron en la obtención de los ejemplares para su análisis. A. O.-P. agradece la beca concedida MECESUP UNATOF 2004 (2004-2005). La financiación de este trabajo ha sido posible gracias a los proyectos AGL20003115-CE y AGL2004-06411-CO2-02/ALI (años 2001 a 2007) (MCYT, MEC); PGIDT01PXI20005PM y PGIDIT05PXIC20002PN (años 2001 a 2008) (Xunta de Galicia, España). Nuestro agradecimiento a los revisores anónimos por sus comentarios y correcciones.

\section{LITERATURA CITADA}

Avise JC. 1994. Molecular markers, natural history and evolution, 511 pp. Chapman \& Hall, New York.

Balech E. 1954. División zoogeográfica del litoral Sudamericano. Revista de Biología Marina 4: 184-195.

Bretos M. 1978. Growth in the keyhole limpet Fissurella crassa Lamarck (Mollusca: Archaeogastropoda) in northern Chile. Veliger 21(2): 268-273.

Bretos M. 1979. Observaciones sobre Fissurella bridgesii Reeve, 1849, en Tarapacá, norte de Chile. Ciencia y Tecnología del Mar 4: 53-60.
Bretos M. 1980. La formación de anillos de crecimiento en Fissurella crassa en el norte de Chile. Boletim do Instituto Oceanografico, Sao Paulo 29(2): 69-71.

Bretos M \& R Chihuailaf. 1990. Biometría y otros aspectos biológicos de Fissurella pulchra (Mollusca: Prosobranquia). Revista de Biología Marina 25(1): 1-14.

Bretos M, J Gutierrez \& Z Espinza. 1988. Estudios biológicos para el manejo de Fissurella picta. Medio Ambiente 9(1): $55-62$.

Castilla JC. 1979. Características bióticas del Pacífico SurOriental, con especial referencia al sector chileno. Revista de la Comisión Permanente del Pacífico Sur 10: 167-182.

Collado GA \& DI Brown. 2003. Structure of the spermatozoa of two sympatric species of Fissurella Brugière, 1789 (Mollusca:Archaegastropoda) from the southeast coast of South America. Invertebrate, Reproduction and Development 43: 237-242.

Collado GA \& DI Brown. 2005. Morphology of the spermatozoon of the limpet Fissurella crassa Lamarck, 1822 (Mollusca: Vetigastropoda). Invertebrate, Reproduction and Developement 47(1): 19-22.

Cracraft J. 1983. Species concepts and speciation analysis. Current Ornithology 1: 159-187.

Espoz C, D Lindberg, JC Castilla \& B Simison. 2004. Los patelogastrópodos intermareales de Chile y Perú. Revista Chilena de Historia Natural 77(2): 257-283.

Guzmán N, S Sáa \& L Ortlieb. 1998. Catálogo descriptivo de los moluscos litorales (Gastropoda y Pelecypoda) de la zona de Antofagasta, $23^{\circ} \mathrm{S}$ (Chile). Estudios Oceanológicos 17: 17-86.

Hall TA. 1999. BioEdit: a user-friendly biological sequence alignment editor and analysis program for Windows 95/98/ NT. Nucleic Acids Symposium Series 41: 95-98.

Hillis DM. 1987. Molecular versus morphological approaches to systematics. Annual Review of Ecology and Systematics 18: $23-42$.

Lancellotti DA \& JA Vásquez. 1999. Biogeographical patterns of benthic macroinvertebrates in the Southeastern Pacific littoral. Journal of Biogeography 26: 1001-1006.

Lowenstam H. 1954. Environmental relations of modification compositions of certain carbonate secreting marine invertebrates. Proceedings of the National Academy of Sciences of the United States of America 40(1): 39-48.

Marincovich L. 1973. Intertidal mollusks of Iquique, Chile. Natural History Museum of Los Angeles County, Science Bulletin 16: 1-49.

McLean JH. 1984. Systematics of Fissurella in the Peruviana and Magellanic faunal provinces (Gastropoda: Prosobranquia). Natural History Museum of Los Angeles County, Contributions in Science 354: 1-70. 
Oliva D \& JC Castilla. 1992. Guía para el reconocimiento y morfometría de diez especies del género Fissurella Bruguiere, 1789 (Mollusca:Gastropoda) comunes en la pesquería y conchales indígenas de Chile central y sur. Gayana Zoología 56(3-4): 77-108.

Olivares A, M Bretos, R Chihuailaf \& A Zenis. 1998. Biometría, hábitat y epibiontes en Fissurella latimarginata (Mollusca: Prosobranchia) en el norte de Chile. Estudios Oceanológicos 17: 95-103.

Olivares-Paz A. 2007. Sistemática molecular del género Fissurella en el Pacífico Sudoriental. Tesis Doctoral, Facultad de Biología, Universidad de Santiago de Compostela, Santiago de Compostela, 285 pp.

Olivares-Paz A, J Quinteiro \& M Rey-Méndez. 2006. Autentificación de lapas del género Fissurella (Mollusca: Vetigastropoda) en la costa chilena. Investigaciones Marinas 34(1): 113-118.

Osorio C, ME Ramirez \& J Salgado. 1988. Gastric content of Fissurella maxima (Mollusca: Archaeogastropoda) at Los Vilos, Chile. Veliger 30(4): 347-350.

Palumbi SR. 1998. Nucleic acid II: the polymerase chain reaction. En: Hillis DM, C Moritz,\& BK Mable (eds). Molecular systematic, pp. 205-247. Sinauer Associates, Sunderland.

Pérez-Farfante I. 1952. Nuevo género y nueva especie del género Fissurella. Revista de la Sociedad Malacológica 'Carlos de la Torre', Habana 9(1): 31-33.

Posada D \& KA Crandall. 1998. Modeltest: testing the model of DNA substitution. Bioinformatics 14: 817-818.

Quinteiro J, J Rodríguez-Castro, J Castillejo, J IglesiasPiñeiro \& M Rey-Mendez. 2005. Phylogeny of slug species of the genus Arion: evidence of monophyly of Iberina endemics and of the existence of relict species in Pyrenean refuges. Journal of Zoological Systematics and Evolutionary Research 43(2): 139-148.

Ramírez-Boehme J. 1974. Nuevas especies chilenas de Lucapina, Fissurella y Collisella (Mollusca, Archaeogastropoda). Boletín, Museo Nacional de Historia Natural, Chile 33: 15-34.
Rozas J, JC Sánchez-del Barrio, X Messeguer \& R Rozas. 2003. DnaSP, DNA polymorphism analysis by the coalescent and other methods. Bioinformatics 19: 24962497.

Saiki RK, DH Gelfand, S Stoffel, SJ Scharf, R Higuchi, GT Horn, KB Mullis \& HA Erlich. 1988. Primer-directed enzymatic amplification of DNA with a thermostable DNA polymerasa. Science 239: 487-491.

Schiaparelli S, M Barucca, E Olmo, M Boyer \& A Canapa. 2005. Phylogenetic relationships within Ovulidae (Gastropoda:Cypraeoidea) based on molecular data from the 16S rRNA gene. Marine Biology 147: 411-420.

Sokolova IM \& EG Boulding. 2004. A neutral DNA marker suggests that parallel physiological adaptations to open shore and salt marsh habitats have evolved more than once within two different species of gastropods. Marine Biology 145: 133-147.

Swofford DL. 2002. PAUP*. Phylogenetics analysis using parsimony (*and other methods).4.0b10. Sinauer Associates. Sunderland. [en línea] < http:// www.paup.scs.fsu.edu/>

Tamura K \& M Nei. 1993. Estimation of the number of nucleotide substitutions in the control region of mitochondrial DNA in humans and chimpanzees. Molecular Biology and Evolution 10: 512-526.

Vegas-Velez M. 1968. Revisión taxonómica y zoogeográfica de algunos gasterópodos y lamelibranquios marinos del Perú. Anales Científicos, Universidad Nacional Agraria, Perú 6(1/2): 1-29.

Vilaxa A \& J Corrales. 1993. Descripción y comentario de la fauna malacológica del sitio Acha-2. En: Muñoz I, B Arriaza \& A Aufderheide (eds). Acha-2 y los orígenes del poblamiento humano en Arica, pp. 81-89. Ediciones Universidad de Tarapacá, Arica.

Wullschleger E \& J Jokela. 2001. Morphological plasticity and divergence in life-history traits between two closely related freshwater snails, Lymnaea ovata and Lymnaea peregra. Journal of Molluscan Studies 68: 1-5. 